\title{
Quantum risks of the extreme temperatures implementation in london
}

\author{
Zhanna Mogiljuk ${ }^{1, *}$ \\ ${ }^{1}$ Moscow State University of Civil Engineering (National Research University) 26, Yaroslavskoye \\ Shosse, Moscow, Russia
}

\begin{abstract}
The article deals with current problems of the road construction projects adaptation to the global climate change realities. It is shown that the existing regulations do not take into account the risks of extreme thermal processes. The method for the events statistical analysis of the extreme temperature realization are presented. The high-resolution statistical studies results of previously unknown regularities of the maximum and minimum temperatures intensity fluctuations evolution in the period from 1973 to 2009 are presented. Quantitative forecasting of tendencies in realization of the maximum and minimum daily temperatures for the period of all life cycle of buildings is shown. These estimates are intended to account for extreme temperature loads in the design of road construction objects and engineering systems. The paper first presented quantum regularities of the air temperature variations in the surface layer of the atmosphere obtained by the author and previously unknown. As an example, the article deals with the statistical analysis of the extreme temperatures variations in London. The graphic materials over the statistical studies of the maximum and minimum temperatures intensity evolution a period of more than 36 years are presented. The results of studies of integral and differential trends into the maximum and minimum temperatures evolution are given. The article deals with the forecast of the warming expected rate in London until 2067.
\end{abstract}

\section{Introduction}

In the last decade, global climate change was under the scrutiny of the global scientific community of international and governmental environmental organizations [1].

The speed of global climate change is becoming a real threat to the safety of the population and the normal functioning security of urban infrastructure and industrial enterprises. In this regard, the road construction projects and urban planning adaptation to the dangerous evolution of climatic processes is the most important task of building science and practice in the XXI century [2].

However, the climate research latest results do not give grounds for optimism. To date, world's leading climate science schools continues fruitless discussion about the direction of the climatic processes evolution vector. For this reason, the critical

\footnotetext{
* Corresponding author: mcxmgsu@mail.ru
} 
increase situation in the climate problem relevance [3], both in Russia and abroad, is not reflected in the current regulatory documents $[4,5]$.

In this regard, currently one of the activity important directions of the scientific school "Macroprofile of microcirculations, microproperties, microeffects and microregularities" are forward-looking study of the construction problems by global climate change $[3,6,10]$. The positive results of the scientific school research in the previously unknown laws field of extreme climatic loads formation on road construction objects are regularly published in specialized scientific journals in Russia and abroad [69]. This article presents the high-resolution statistical studies results in the temperature loads evolution laws field over the past 36 years on the example of the London city. This article presents the materials of verification of the discovery by the authors of quantum laws in different geographical locations of the Earth. Therefore, its text and formulas use the same verbal and mathematical justifications and expressions.

\section{Studies of the temperature loads evolution in London}

To study climatic load evolution the authors used the official data of meteorological observations for the period from 01.01.1973 to 01.01 .1994 (7670 days) as the historical data for maximum and minimum temperatures in London and the data on the current state of climatic processes for the period from 08.31.1994 to 08.31.2009 (5480 days). These data cover the observation period of more than 36 years. In connection with the different length of the observations historical and current arrays was previously carried out the normalization of the second array.

One of these studies results is shown in Figure 1 in the form of statistical dependence graphs of the realizations frequency of maximum and minimum temperatures in London on the temperature values for the last 36 years with a resolution $\Delta \mathrm{t}=0.1^{\circ} \mathrm{C}$.

As a result, the comb-like form of the statistical distribution of the temperatures realization frequency on the temperature scale $\left(0.1^{\circ} \mathrm{C}\right)$ was obtained, as shown in Figure 1.

As we can see at the thin curves in Figure 1a, the temperature increment between the peaks of the statistical distribution of events realizing the maximum temperature, for example in the range of $-5^{\circ} \mathrm{C}$ to $+33^{\circ} \mathrm{C}$, in the averages is $1.00^{\circ} \mathrm{C}$. 


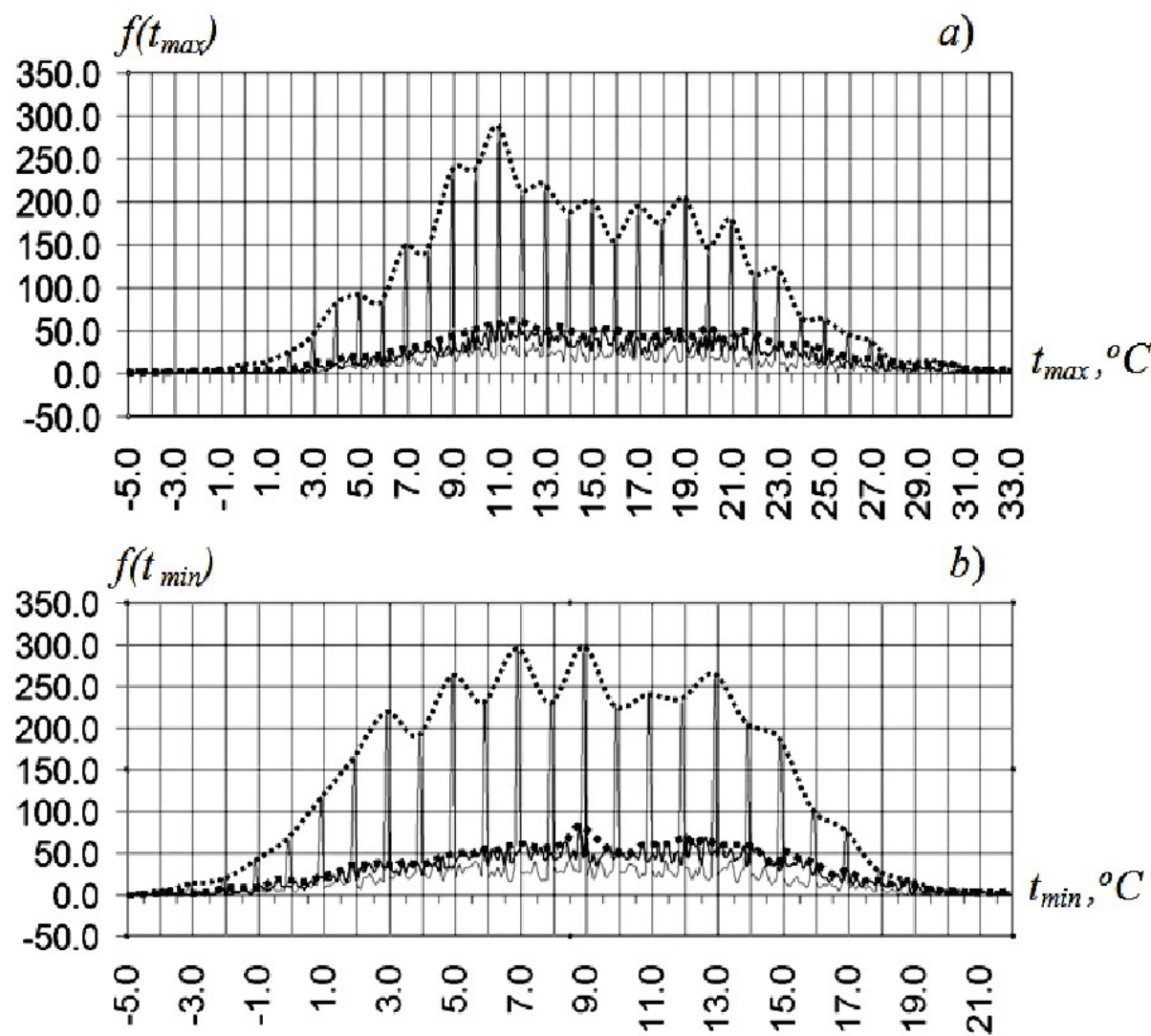

Fig. 1. Statistical distribution curves on a temperature scale the realizing events number of the maximum $(a)$ and minimum $(b)$ daily temperatures, $f\left(t_{\max }\right)$ and $f\left(t_{\min }\right)$, in London: the thin lines show the curves corresponding to data in the period from 01.01.1973 on 01.01.1994 and the thin bold line in the period from 31.08.1994-31.08.2009; bold lines represent the envelope curves of the corresponding statistical distribution

As we can see also at the thin curves in Figure $1 \mathrm{~b}$, the temperature increment between the peaks of the statistical distribution of minimum temperatures, in the range from $-5^{\circ} \mathrm{C}$ to $+21^{\circ} \mathrm{C}$, also in the averages is $1.00^{\circ} \mathrm{C}$.

We discussed below the possibility of using statistical regularities in the distribution of the events frequency on the temperature scale to predict the expected temperature trend in the context of global climate change.

To this end, we will further analyze the curves of integral $I\left(t_{\max }\right)$ and $I\left(t_{\min }\right)$ in Figure 2 and differential $D\left(t_{\max }\right)$ and $D\left(t_{\min }\right)$ thermal processes in Figure 3.

For this reason, we will further analyze the curves of integral and differential thermal processes in Figure 2. The graph of the integral trend for the maximum temperatures is a function

$$
I\left(t_{\max }\right)=\sum_{m=1}^{m}\left[f_{2 m}\left(t_{\text {max }}\right)-f_{1 m}\left(t_{m \text { max }}\right)\right] t_{m \text { max }}
$$


where $t_{\max }, m, M, f_{1 m}, f_{2 m}, t_{m \max }$ - the current variable scale of the maximum temperature in the ${ }^{\circ} \mathrm{C}$, the current $\mathrm{m}$ and maximum $\mathrm{M}$ number of the mesh count of the maximum temperature in the range of values $t_{\max }$ for which $\left[f_{2 m}\left(t_{\max }\right)-f_{1 m}\left(t_{m \text { max }}\right)\right] \neq 0$, the first data array about the frequency of daily maximum temperatures implementation in the period from 01.01.1973 to 01.01.1994, the second array data about the frequency of daily maximum temperatures implementation in the period from 08.31.1994 to 08.31.2009, the temperature in ${ }^{\circ} \mathrm{K}$.

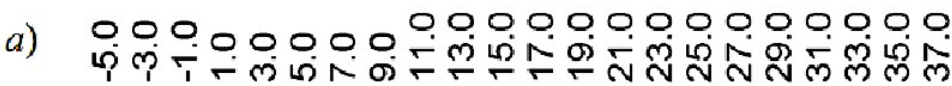

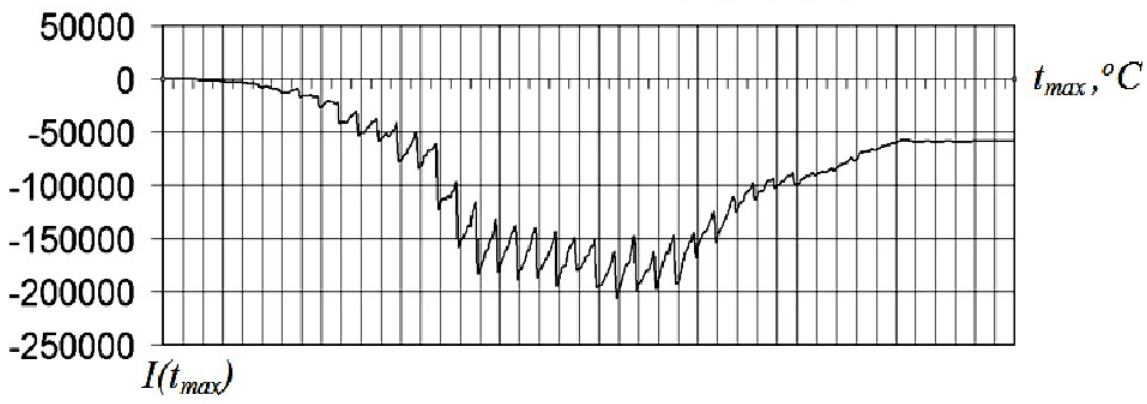

b) 욱 우

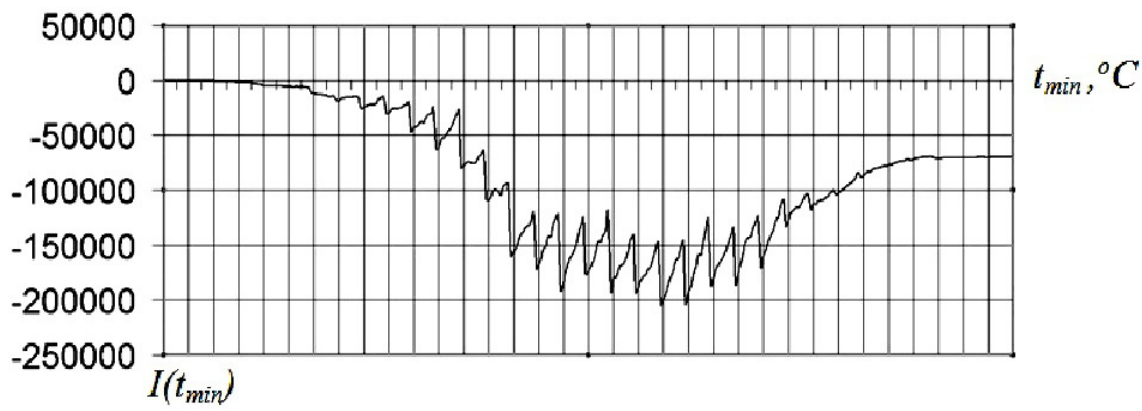

Fig. 2. Graphic of integral trends for maximum (a) and minimum (b) temperatures

By analogy with (1) the graph of the integral trend for minimal temperatures can be represented by the function

$$
I\left(t_{\text {min }}\right)=\sum_{n=1}^{n}\left[f_{2 n}\left(t_{\text {min }}\right)-f_{1 n}\left(t_{n \text { min }}\right)\right] t_{n \text { min }}
$$

The unit of the measurement calibrated integral trends is [deg $\times$ day], and the value of the integral trend shows the total increase or decrease in the intensity of heating of the atmosphere in the range of maximum or minimum temperatures from $m=1$ up $m$ or from $n=1$ up $n$.

Moreover, the values of integral trends for the entire period of the meteorological observations taken into account shows the total increase or decrease in the intensity of atmosphere heating in the entire range of maximum and minimum temperatures. 


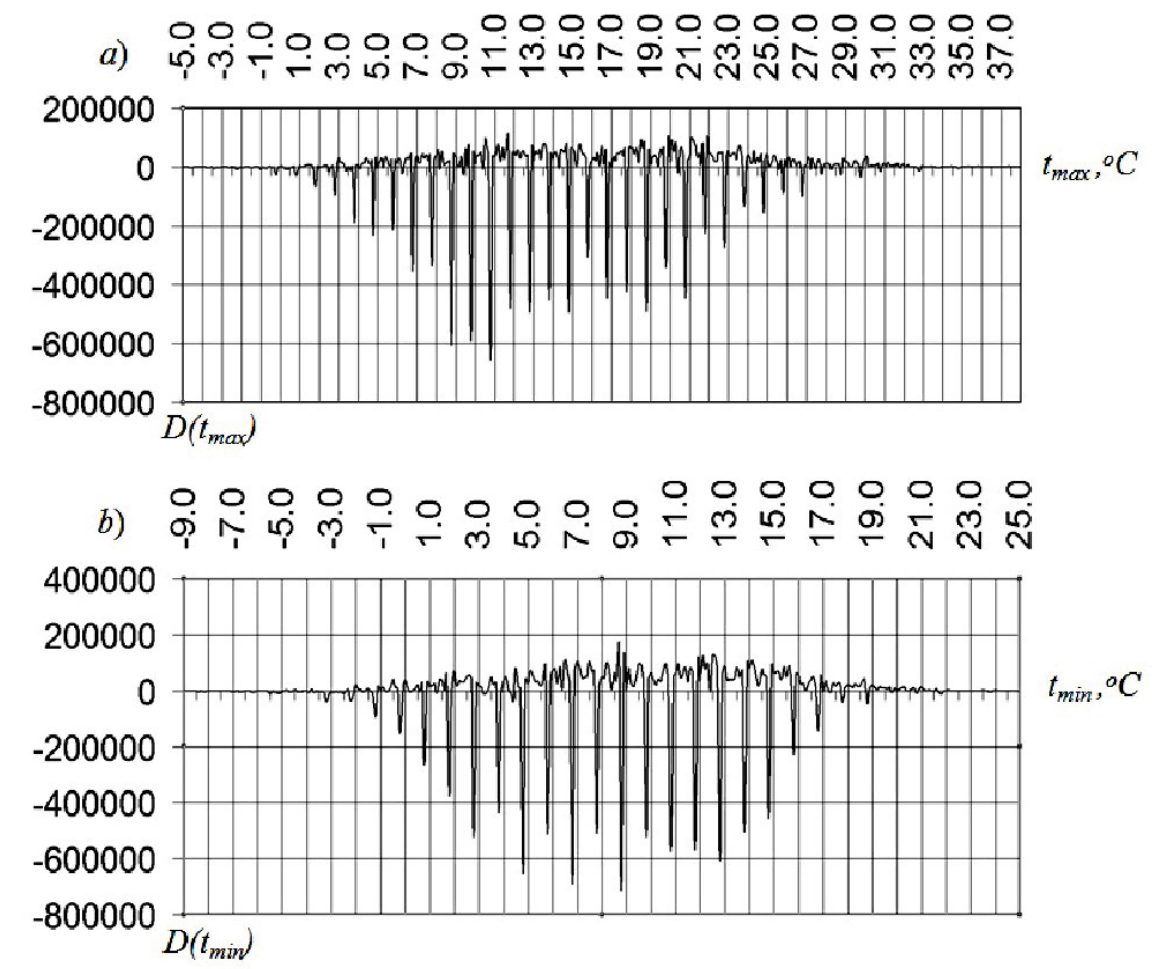

Fig. 3. Graphics of differential trend in the maximum (a) minimum and (b) temperatures in London during the period from 01.01.1973 on 31.08.2009.

It should be noted that the step of $0.1^{\circ} \mathrm{C}=0.1^{\circ} \mathrm{K}$ for the summation in (1) and (2) was chosen to improve the accuracy of summation, this will use in future in the subsequent calibration of the integral trends values.

Since the summation step is $0.1^{\mathrm{O}} \mathrm{C}=0.1^{\mathrm{O}} \mathrm{K}$, then for further use $I\left(t_{\max }\right)$ it is necessary to calibrate the integral trend values by the unit of measurement of the maximum temperature scale equal to $1^{\mathrm{o}} \mathrm{C}=1^{\mathrm{o}} \mathrm{K}$.

In according $I\left(t_{\max }\right)$ to the formula $\bar{I}\left(t_{\max }\right)=I\left(t_{\max }\right) / 10$; in according $I\left(t_{\min }\right)$ to the formula $\bar{I}\left(t_{\min }\right)=I\left(t_{\min }\right) / 10$.

The curves in Figure 2 allow us to conclude that according to the schedule of the integral trend we see growth of the calibrated intensity of the cooling is -5810.2 [deg $\times$ days] during the period observed, for the entire range of the maximum temperature implementations, or an average of $-0.76{ }^{\circ} \mathrm{C}$ for 22 years. For minimum temperatures, we see increase of the calibrated intensity cooling is -6977.0 [deg $\times$ day] for the same period or an average of $-0,91{ }^{\circ} \mathrm{C}$ for 22 years.

If these trends continue in the next 50 years (until 2067), then we can expect a decrease in the values of daily maximum temperatures in London by $-1.73^{\circ} \mathrm{C}$, and the minimum - by $-2,1^{\circ} \mathrm{C}$.

The functions of the differential trends of maximum (Figure $3 a$ ) and minimum (Figure $3 b$ ) temperatures are determined by equations:

$$
D\left(t_{\max }\right)=\left[I_{2 m}\left(t_{\max }\right)-I_{1 m}\left(t_{m \max }\right)\right] / \Delta t_{\max },
$$




$$
D\left(t_{\min }\right)=\left[I_{2 n}\left(t_{\min }\right)-I_{1 n}\left(t_{n \min }\right)\right] / \Delta t_{\min },
$$

where $\Delta t_{\text {max }}=\Delta t_{\text {min }}=0.1^{\circ} \mathrm{C}$.

For possible other calculations, the functions of the differential trends can also be calibrated to the unit of temperature measurement $1^{\circ} \mathrm{C}=1^{\circ} \mathrm{K}$ with using formulas:

$$
\bar{D}\left(t_{\max }\right)=D\left(t_{\max }\right) / 10 \text { and } \bar{D}\left(t_{\text {min }}\right)=D\left(t_{\min }\right) / 10
$$

\section{Formulation and theoretical proof of the quantum hypothesis based on the laws analysis of extreme temperatures implementation in London}

In accordance with the molecular kinetic theory of the gases the temperature depends proportionally on the kinetic energy of molecules and, as a consequence, on the velocity of their motion.

On the other hand, according to the basic law of quantum mechanics, to change the speed of a microparticle (in this case, a molecule) it is necessary to give it a momentum equal to the Planck's constant $\hbar=1,054571726 \times 10^{-34} \mathrm{~J} \times \mathbf{S}$.

According to the results obtained (Figure 1) the comb-like form of the statistical distribution of the temperatures realization $[6,7,10]$ confirms the possibility of formulation of the existing hypothesis of the previously unknown quantum law of the temperatures values realization in the near-surface layer of the atmosphere. According to the quantum theory, the minimum increment of the moment of momentum molecule is possible if it is equal to (or more than) Planck constant, that is

$\hbar=\frac{2 * 3 \mathrm{k} \Delta \operatorname{Tr}}{v}$.

It follows from equation (6) that the temperature increment is possible if

$$
\Delta \boldsymbol{T}=\frac{\hbar}{2 \boldsymbol{r}} \sqrt{\frac{\mathrm{T}}{3 k \boldsymbol{m}}} .
$$

Thus, the temperature increment between the peaks on Figure 1 obtained from the official data of field meteorological observations differs from the theoretical value according to the quantum hypothesis (6) for no more than $2 \%$. Similar values obtained by the authors with small deviations (less 10\%) in other cities of the planet (Anchorage, Canberra, Moscow, Niamey, New York, Tokyo, etc.) also confirm the real existence of the fundamental quantum regularity of the temperature increments formation in the surface layers of the atmosphere.

For this assessment, we use the average value of the molecule mass and the average distance between molecules for atmospheric air:

$$
\Delta \mathrm{T}=\frac{\hbar}{2 \mathrm{r}} \sqrt{\frac{\mathrm{T}}{3 \mathrm{~km}}}=\frac{1,05^{*} 10^{-34}}{2 * 7,2 * 10^{-10}} \sqrt{\frac{\mathrm{T}}{3 * 4,83 * 10^{-26} * 1,38 * 10^{-23}}}\left[{ }^{\circ} \mathrm{C}\right]=\frac{1,05 * 14}{14,4}\left[{ }^{\circ} \mathrm{C}\right]=1,02^{\circ} \mathrm{C} \text {. }
$$

In this regard, the value of the temperature quantum increment can vary within $\pm 10 \%$ depending on fluctuations in the atmosphere composition, for example, due to fluctuations of humidity or concentration of aerosols.

\section{Conclusion}

The results of the variations statistical study in the maximum and minimum daily temperatures in London from 1973 to 2009 showed that for this region of the Earth 
global climate change is manifested in the form of an increase of intensity of the atmosphere surface layer cooling over the observed period. For maximum temperatures this decrease averages is $-0,76^{\circ} \mathrm{C}$ for 22 years. For minimum temperatures this decrease averaging is $-0,91{ }^{\circ} \mathrm{C}$. An integrated assessment of the cooling trend in London shows that an decrease in the daily maximum temperature loads for road and buildings in London by $-1,73^{\circ} \mathrm{C}$ and for the minimum by $-2,1^{\circ} \mathrm{C}$ can be expected in the next 50 years. According to simultaneous studies of the evolution of temperature loads, which were carried out by the authors, in other regions of the planet, for example, in Canberra or Moscow or Niamey, there is an opposite trend, when there is a increase in the intensity of heating of the surface layer of the atmosphere. This suggests that the influence of global climate change on temperature changes in different regions of the Earth is uneven.

Along with this, statistical studies of maximum and minimum temperature fluctuations in London from 1973 to 2009 confirmed the action of the previously unknown fundamental quantum regularity in the implementation of the events of formation of maximum and minimum daily temperature values $[9,10]$.

Taking this into account, the results given in the article can be useful both for updating the existing normative and technical documentation and for their application in the design of road and buildings for assessing the maximum number of defrosting cycles of road building materials. In addition, they can be used to adapt engineering systems of heat and energy supply, energy saving, ventilation and Sewerage to global climate change, which manifestations opposite for different regions of the Earth. Similar materials of temperature manifestations research of global climate change in other regions of the planet will be published by the authors in a special series of articles.

\section{References}

1. Climate Change 2103, Cambridge, University Press, 1536 p. (2013)

2. Managing the Risks of Extreme Events and Disasters to Advance Climate Change Adaptation, Cambridge, University Press, 582 p. (2012)

3. M.S. Khlystunov, V.I. Prokop'ev and Zh.G. Mogiljuk The global evolution regularities of the climatic loads and impacts, Moscow, NR MSUCE, 193 p. (2015)

4. Russian Norm SP 20.13330.2016 Loads and impacts (Moscow: Minstroy) p 104

5. Russian Norm SP 131.13330.2012 Building climatology (Moscow: Minregion) p 113

6. M. Khlystunov, V. Prokop'ev and Zh. Mogiljuk Tall Buildings 3 132-134 (2014)

7. M. Khlystunov, V. Prokop'ev and Zh. Mogiljuk WASJ 269 1219-1223 (2013)

8. M. Khlystunov, V. Prokop'ev and Zh. Mogiljuk Mod. App. Sc. 9 1 96-102 (2015)

9. Zh. Mogiljuk and M. Khlystunov MATEC Web Conf. 10602013 (2017)

10. Hlystunov M and Mogiljuk Zh 2018 IOP Conf. Series: Materials Science and Engineering 456, 012056 (2018) 